\title{
California's agricultural regions gear up to actively manage groundwater use and protection
}

by Thomas Harter

New regulations are emerging in response to historic groundwater depletion and widespread groundwater quality degradation in California. They aim at long-term preservation of groundwater resources for use in agriculture, in urban areas and for the support of ecosystems in streams dependent on groundwater. The regulations are driving a historic shift in the way the agriculture sector is engaged in managing and protecting groundwater resources in California. A review and synthesis of these recent regulatory developments - the Sustainable Groundwater Management Act and new policies under the California Porter-Cologne Water Quality Control Act — clarifies key challenges for farmers, scientists and regulators and points to the need for continuing innovation in agricultural practices as well as in planning and policy.

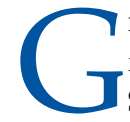
roundwater is a critical resource for California water management. Stored in aquifers, water from rainy seasons can be used during dry and hot summers and supports water users

Online: http://californiaagriculture.ucanr.edu/ landingpage.cfm?article=ca.v069n03p193\&fulltext=yes doi: 10.3733/ca.E.v069n03p193 through droughts if it is replenished in wet years. Aquifers also help move water from areas of recharge (often on the edge of the valley floor near the foothills) to areas dominated by extraction that are miles or - in very large aquifers - a few tens of miles away. Unfortunately, in many areas of California we have not been replenishing this account sufficiently during wet years. Groundwater resources across California's agricultural regions have been more stressed during the current drought than at any other time in history (CDWR 2014a).

In most wells, depth to groundwater has exceeded that of the same or nearby wells in the 2007-2009 drought, and exceeds the depths recorded in the mid-20th century, prior to local, state and federal water projects (reservoirs and canals) coming on-line. The demand for groundwater has been increasing due to the increased acreage of intensively grown crops, large-scale conversion of rangeland and field crops to permanent crops and uncertainty about water deliveries from the Sacramento-San Joaquin Delta, the heart of California's elaborate surface water conveyance system (CDWR 2014b).

The Kings River flows across a coarse gravel bed near the Sierra Nevada foothills, recharging groundwater. 
California Gov. Jerry Brown signed the new groundwater legislation into law in September 2014

Lower groundwater levels have significantly increased pumping costs and increased the need for constructing deeper wells where existing wells were not sufficiently deep to access falling water levels (Howitt et al. 2014; Medellín-Azuara et al. 2015). Greater reliance on groundwater during the drought has caused land subsidence on a large scale in the Central Valley (in some cases more than 12 inches of subsidence in 2014 alone), coastal basins and Southern California; it has also exacerbated seawater intrusion where (CDWR 2014c). As pumping lowers the water table, water quality is sometimes compromised by saline water or other naturally occurring contaminants (e.g., Jurgens et al. 2010). Rapidly falling water tables also lead to more-contaminated shallow groundwater entering drinking water wells.

Agricultural regions in California are challenged not only by dwindling groundwater supplies - a critical drought insurance for California - but also by significant groundwater quality degradation, in particular from nitrate pumping occurs in aquifers near the coast

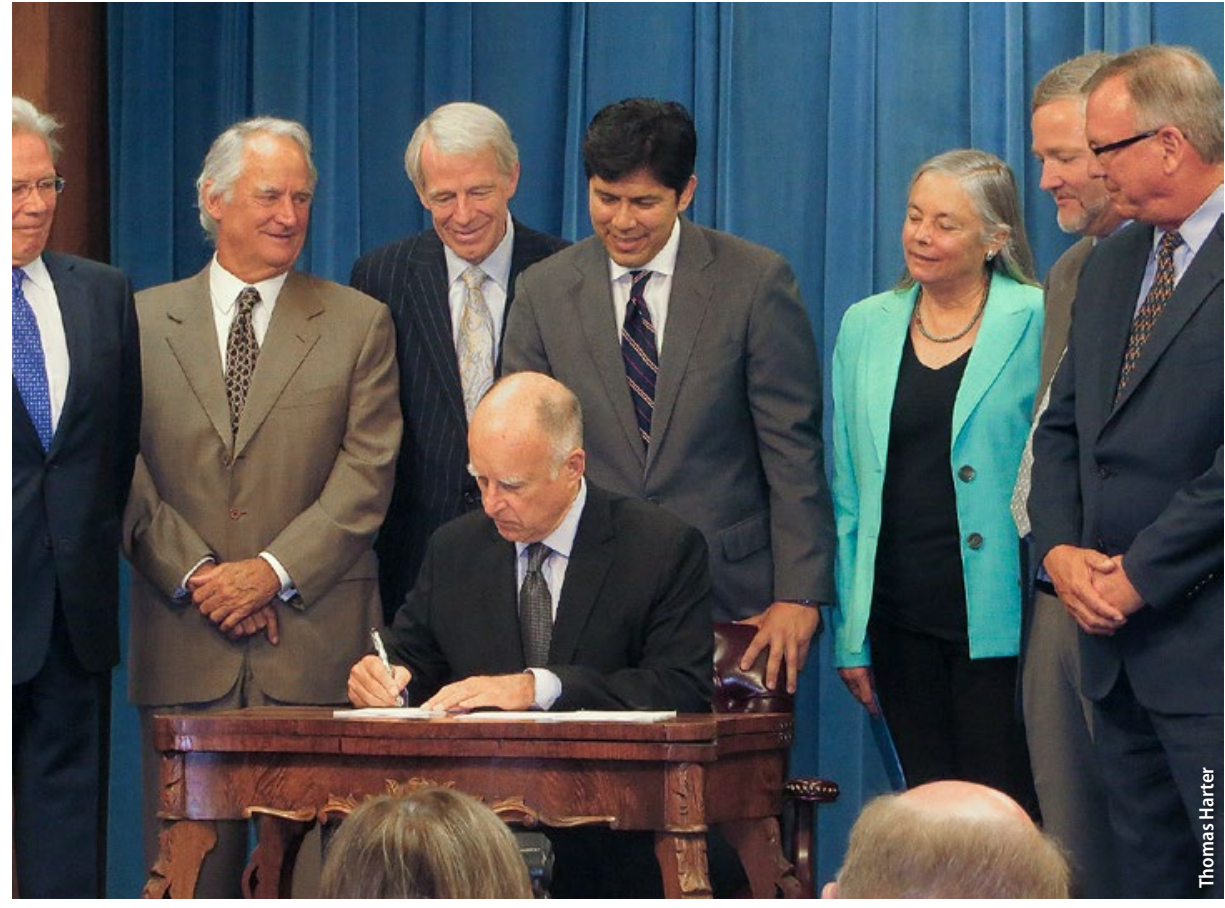

and salt pollution. Pollutants may come from urban sources (such as wastewater treatment and food processing plants), domestic household sources (such as septic systems) or agricultural sources (such as fertilizer, animal manure and irrigation water).

A number of studies have shown a high incidence of nitrate, above drinking

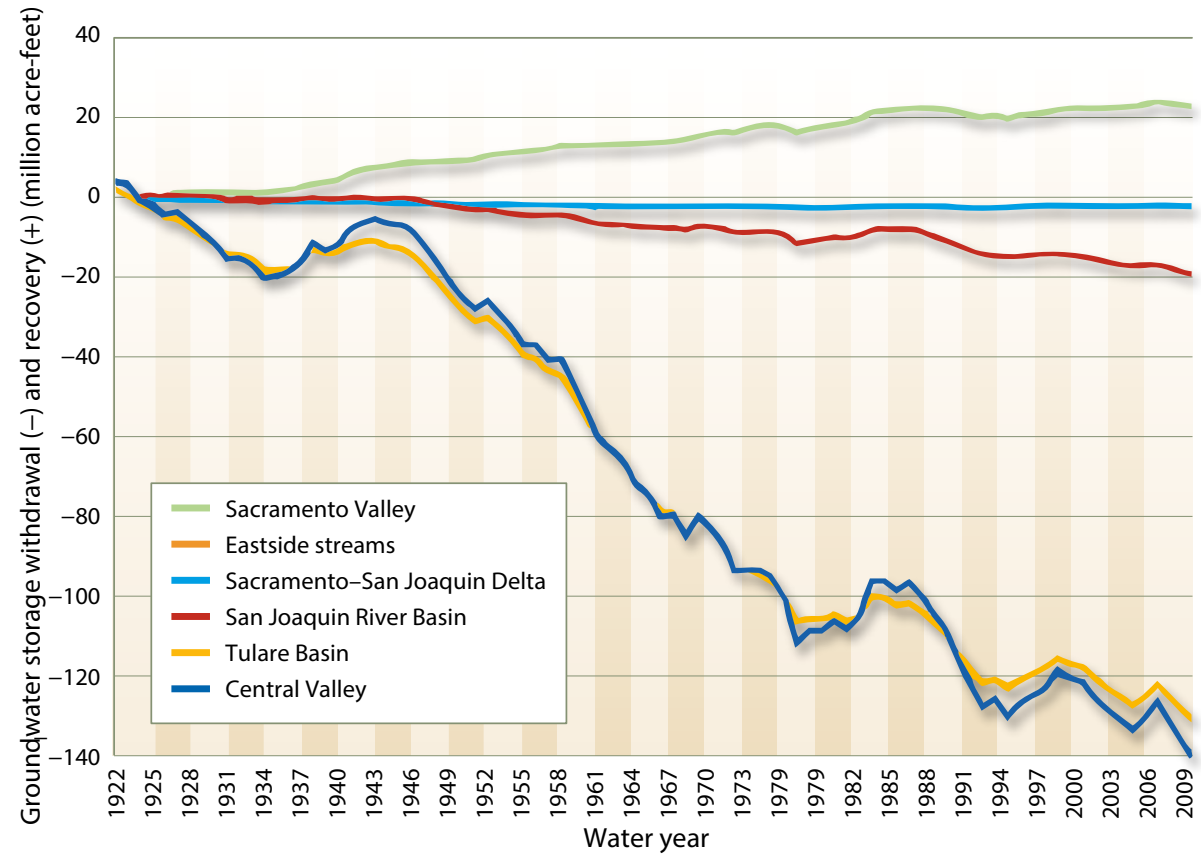

Fig. 1. Changes in groundwater storage in the California Central Valley (dark blue) and its subregions from 1922 to 2009 (adapted from Brush 2014). The largest depletions have occurred in the Tulare Lake Basin, which includes the southern part of the Central Valley from Fresno to Bakersfield. water standards, in domestic and public drinking water supply wells; in some counties, more than $40 \%$ of domestic wells exceed the nitrate limit for safe drinking water (Harter et al. 2012; Lockhart et al. 2013; LWA 2013; SWRCB 2013). Salt accumulation in streams and groundwater has also been found to be significant (LWA 2013), with potentially punitive economic consequences: By 2030, the combined impact of surface water and groundwater salinization to agriculture and the California economy, if current conditions continue and no preventative action is taken, is estimated at $\$ 6$ to $\$ 10$ billion annually in lost production costs, job losses and other impacts (Howitt et al. 2009).

The problems of groundwater overdraft and water quality degradation have been recognized for some time. Increasing public concern over the past two decades has raised the level of local, state and federal government engagement and of actions by policy- and decisionmakers. Groundwater users and wastewater dischargers in the urban and the agricultural sectors face new regulatory requirements. While urban governments have a long history of dealing with limited water resources, the agricultural community is experiencing significant and historic changes in its involvement with managing groundwater extraction and protecting groundwater resources for the future. 


\section{Groundwater supply management}

On September 16, 2014, Gov.

Jerry Brown signed the Sustainable Groundwater Management Act (SGMA), California's first comprehensive groundwater management legislation. It focused on managing groundwater supplies as part of an integrated hydrologic system for the benefit of current and future generations of Californians.

The legislation and the governor's water action plan (California Natural Resources Agency 2014) recognize the importance of groundwater for California's livelihood and its central role in California water management. The legislation seeks to put a process in place that ends decades of unsustainable groundwater use and management in some California regions and prevents future unsustainable groundwater use in other regions. For example, an estimated 140 million acre-feet were depleted from the Central Valley aquifer system (mostly in the Tulare Lake Basin) between 1922 and 2010 (fig. 1). And seawater intrusion due to groundwater pumping has migrated 8 miles into the Salinas Valley aquifer system (fig. 2).

While other Western states have statewide water rights management systems that include groundwater, California has lacked an administrative approach to managing groundwater rights. Conflicts that have arisen among groundwater users, for example in some areas in urban Southern California, have been addressed through expensive and lengthy judicial proceedings called groundwater basin adjudications.

The core principles that guided the development of the new legislation include the following:

- A vision that groundwater is best managed and controlled at the local or regional level; the state would only step in if local efforts are not successful or are not moving forward in accordance with the law.

- A broad definition of groundwater sustainability and a specific outline of what undesired effects must be avoided. The latter include continuous water level drawdown, subsidence, seawater intrusion, water quality degradation and continued (or new) impacts to groundwaterdependent ecosystems and streams after Jan. 1, 2015, when the legislation took effect.

- The state's role is focused on providing clear guidelines on requirements for local groundwater management, to be developed in 2015 and 2016 by the

\section{The agricultural community is experiencing significant and historic changes in its involvement with managing groundwater extraction and protecting groundwater resources.}

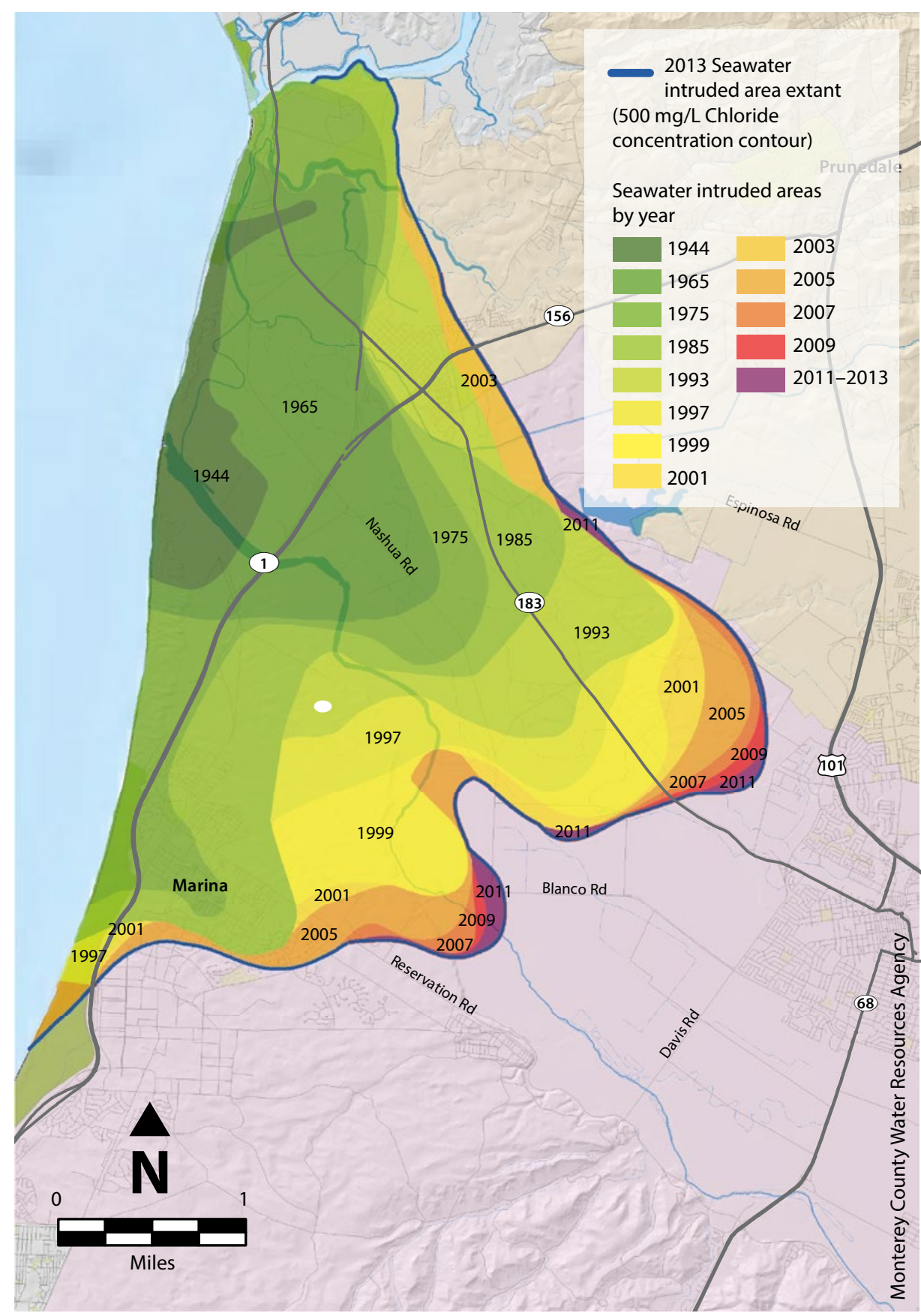

Fig. 2. History of seawater intrusion in the Salinas Valley (Brown and Caldwell 2015).
Department of Water Resources, as well as providing technical and financial support.

- Existing water rights will continue to be protected.

.


Based on these principles, the legislation lays out a framework for the entire state to manage its groundwater. In 127 medium- and high-priority groundwater basins (representing about $96 \%$ of groundwater extraction), groundwater sustainability agencies (GSAs) will have to be formed no later than June 2017. These GSAs will be responsible for developing and implementing a groundwater sustainability plan (GSP) that has specific objectives and meets specified sustainability targets consistent with the core principles of the SGMA. GSAs have 3 to 5 years to develop and begin implementing their GSP (by 2022, or in critically overdrafted basins by 2020). GSAs must show significant progress in implementing their plan and achieve sustainability no later than 2042.

Between 2015 and 2017, the focus of the implementation of the SGMA will be multipronged:

- GSAs will be formed that together govern all of the 127 medium- and high-priority groundwater basins, not just partially but in their entirety. This process will only be possible with significant local stakeholder involvement and will require significant outreach, facilitation and local leadership.

- The Department of Water Resources will be in charge of identifying critically overdrafted basins, developing minimum regulations for a GSP, new rules for adjusting basin boundaries and implementing basin coordination among GSAs, and regulations for determining medium- and high-priority basins that have significant groundwater-dependent ecosystems or stream flow but are not already included in the current group of 127 medium- and high-priority basins.

- Technical guidelines and financial support will be developed throughout the state.

While farmers and landowners may not see immediate impacts from the legislation, their involvement in the formation of the GSAs and in the development of the GSPs provides opportunities to shape the political process in ways typically not possible in the court-driven adjudication process. GSAs can be formed by local public agencies, such as cities, counties, water and irrigation districts, or other special acts districts (e.g., water replenishment districts).

The SGMA provides flexibility and allows for either a single agency or multiple agencies to run a GSA. A GSA in turn may govern an entire groundwater basin or just a portion of a groundwater basin. Where multiple GSAs govern a groundwater basin, GSAs have to coordinate their efforts. A basin may have a single GSP implemented by one or multiple GSAs, or a GSA may have multiple GSPs. Importantly, the GSAs must consider the interests of the wide range of groundwater uses and users, including agricultural pumpers. Given the broad authorities given by the SGMA to GSAs in managing recharge and extraction, groundwater users have strong motivation to be engaged early in the formation of GSAs to ensure political representation in the decisionmaking process when GSPs are developed and implemented. GSPs will rank around four key programmatic areas:

- data collection, monitoring, modeling, evaluation, assessment and reporting (on a continuous basis)

- stakeholder engagement, communication, outreach and facilitation of stakeholder-informed policy development

- development of groundwater supply projects to increase recharge as needed (e.g., intentional recharge, groundwater banking, increased recycled water use, storm water capture, surface water imports)

- reducing groundwater extraction as needed (e.g., water conservation programs, land purchases for agricultural land retirement, setting extraction limits, extraction fees)

Funding for GSP activities will likely come from a combination of state and local funding sources.

In overdrafted basins, adjudications may continue to be an alternative process to achieve sustainability, despite the high cost and often years-long legal proceedings involved. As of this writing, the Legislature is actively considering multiple bills that would create an alternative, streamlined adjudication process.

In the intermediate and long run, the main impact from this legislation will be that new recharge and groundwater storage options will be pursued, and, where needed, pumpers may see restrictions in pumping or well drilling. Where additional recharge is available, pumpers may be asked to pay additional costs to secure the recharge needed in return for their right to continue pumping. Basin boundaries may be adjusted and may include fractured rock aquifers currently not recognized as groundwater basins by the Department of Water Resources although they are subject to significant groundwater extraction in some areas.

Litigation and state intervention may be inevitable in some cases, but it remains to be seen how frequently that route will be chosen over mediation or facilitated GSP development and implementation. In either case, the new groundwater legislation marks a turning point in California water management by no longer allowing for continued depletion of groundwater resources and by requiring an active, well-informed groundwater management system that is better integrated with surface water management, water quality management and land use decisions to maintain a balance that best serves competing human, economic and environmental health interests.

\section{Groundwater quality regulation}

The federal Clean Water Act addresses only surface water quality. By contrast, California's water quality law, the PorterCologne Water Quality Control Act of 1969 (Porter-Cologne Act), includes the protection of groundwater quality. The California Legislature designated the State Water Resources Control Board (SWRCB) and nine newly created regional water boards (RWBs) to implement the Porter-Cologne Act.

The primary function of the RWBs is to establish a basin plan that identifies water quality goals and to develop regulatory programs to achieve those goals. Nonpoint sources of potential groundwater pollution (urban storm water, agriculture) were long exempted from direct oversight through unconditional waste discharge waivers. However, those waivers were discontinued by the Legislature in 2002, which led to new regulatory requirements for agricultural and other nonpoint source water dischargers (Dowd et al. 2008). Focused on surface water quality in the first decade after 2002, these regulatory efforts now increasingly address groundwater quality. They require 
demonstrable source control and documentation of groundwater nitrate and salt discharges and also provide state and federal funds to improve the drinking water supplies of communities affected by poor groundwater quality.

The nine RWBs use different approaches to assess and control agricultural discharges. The Central Valley RWB and Central Coast RWB regions are home to large areas of California's most intensive agricultural operations and have therefore developed the most extensive regulations. But all RWBs are obligated to consider discharges from nonpoint sources to groundwater and to develop basin plan amendments for nutrient and salt management (SWRCB 2009).

In the Central Valley, three major programs have been or are being developed to control salt and nutrient discharges to groundwater and surface water: the Central Valley Dairy Order, the Irrigated Lands Regulatory Program (ILRP) and the Central Valley Salinity Alternatives for Long-Term Sustainability (CV-SALTS) program. The Central Coast has developed its own version of the ILRP, referred to as the Central Coast Agricultural Order.

With respect to groundwater protection, all of the above programs have in common that they require

- assessment of sources, groundwater pathways (hydrogeology, water quality) and potential groundwater quality impacts

- source management plans

- source management certification and reporting

- direct or indirect (proxy) groundwater discharge monitoring

- development of management practices that are protective of groundwater quality

- groundwater monitoring at the regional level

Central Valley Dairy Order. The 2007

Dairy Order was the first comprehensive California groundwater quality permitting program applicable specifically to farms. It sets the framework for permitting dairy discharges of nutrients and

Water well drilling rig on the UC Davis campus. salts to surface water and groundwater. The dairy order requires dairies to prepare nutrient and waste management plans, annually report nutrient budgets for individual fields, tonnage of manure exports and water quality of on-site wells. Targeted shallow groundwater monitoring and efforts to develop improved management practices that demonstrably improve groundwater quality are implemented through the Central Valley Dairy Representative Monitoring Program. This program is led by a coalition of dairy producers that is working closely with the RWB; it offers an efficient alternative to individual dairy groundwater monitoring plans.

\section{Central Valley Irrigated Lands}

Regulatory Program. Upon its inception in the early 2000s, the Central Valley ILRP (like a similar program in the Central Coast region) focused on surface water and watershed protection through farmer education, certification and coalition-led stream water quality monitoring and management. But since 2010, the Central Valley RWB has been expanding the ILRP to add elements that also protect and improve groundwater quality, primarily nitrate, pesticide and salt contamination, through source management on irrigated lands.

In the Central Valley, the ILRP covers about 7 million irrigated acres with several tens of thousands of individual farms. Permits (waste discharge orders) are given either to individual farms or to regional ILRP coalitions, organizations that farms can join to represent them collectively with the RWB. ILRP coalitions representing large groups of farmers include the Sacramento River Watershed, Rice Farmers, Eastern San Joaquin Watershed, San Joaquin County and Delta, Western San Joaquin Watershed, Tulare Lake Basin Area, and Western Tulare Lake Basin Area coalitions. Each coalition is subject to a separate RWB order.

Under the expanded ILRP, the first step is a Groundwater Assessment Report (GAR), which is currently being developed or has been developed by each of the coalitions. The assessment identifies

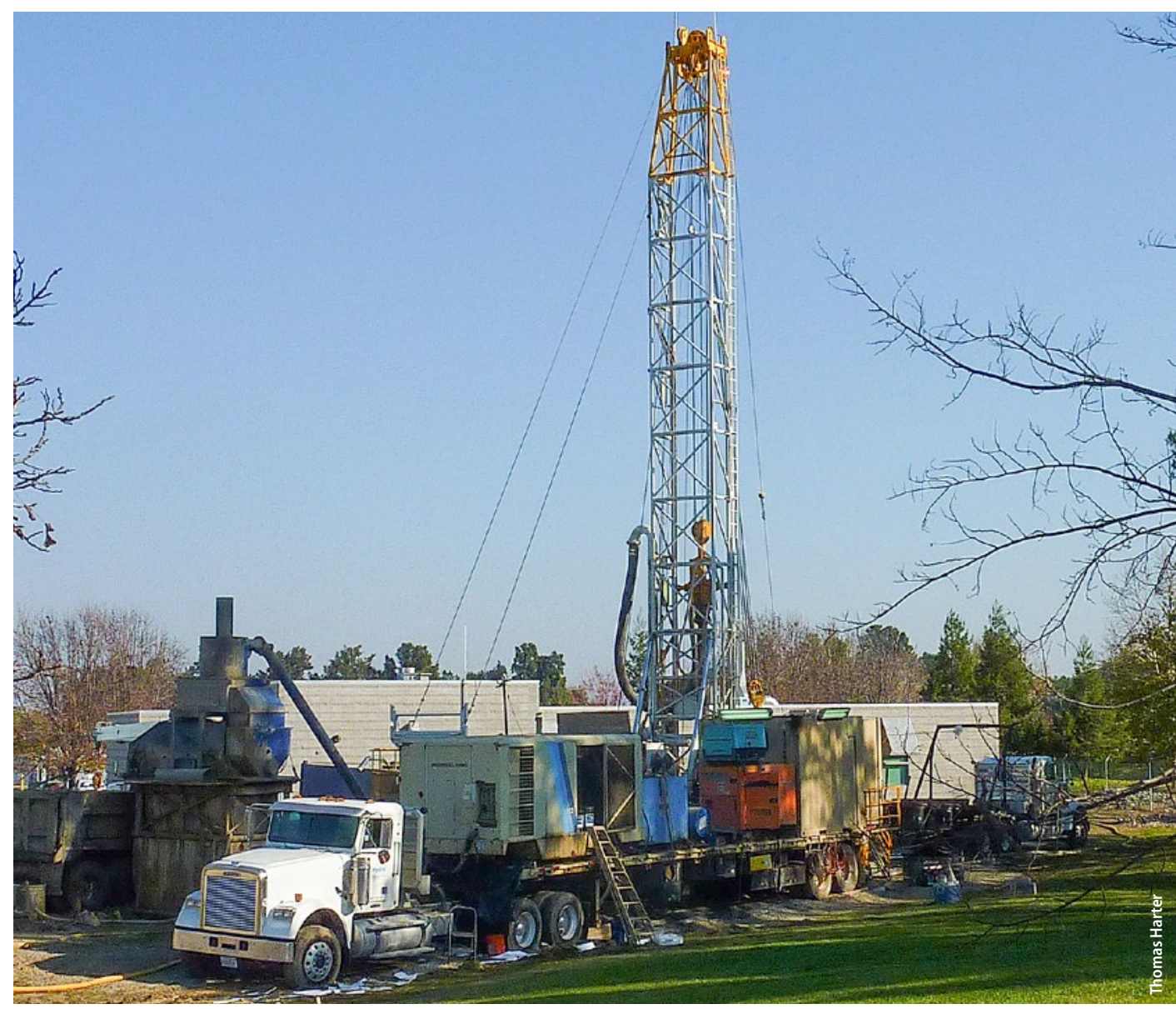


historic and current groundwater quality conditions and identifies vulnerable groundwater regions. The assessment provides the rationale for the monitoring and reporting requirements, which may differ within and between regions, and allows for a tiered program of monitoring and reporting requirements for subregions to reflect the diverse potential impacts to groundwater.

In a next step, beginning in 2015, fieldspecific nutrient management planning forms will need to be completed by all farmers for the first time. Generally, farmers will now be required to implement management practices, keep appropriate records (for random audits) and report some of the information collected to their coalition. The coalitions are further responsible for performing groundwater monitoring, typically in a network of domestic and monitoring wells. As in the dairy program, the coalitions are also responsible for developing management practices that demonstrably improve and protect groundwater quality. A significant focus will be on documenting field nitrogen inputs and outputs and on improving nitrogen-use efficiency.

Central Coast Agricultural Order. In 2012, the Central Coast RWB adopted an update to the ILRP, called the Agricultural Order (or Agricultural Regulatory Program). The program covers about 4,000 farms on about 400,000 acres. Based on its own groundwater assessment work, the RWB created three tiers of farms depending on the potential risk they pose to groundwater quality. The tiers are determined by pesticide use, farm size, nitrate occurrence in nearby public supply and farm wells, and by crop type. About one in seven farms are in the highest tier, tier three (posing the greatest risk), about half of the farms, mostly vineyards, fall in the lowest tier (posing the least risk), and the remainder are in tier two.

As in the Central Valley, farms in all tiers are required to perform proper nutrient, pesticide and irrigation management, documented in their farm plans (although the specific forms may differ from those in the Central Valley). Backflow prevention and proper well abandonment are also required on all farms. Unlike in the Central Valley ILRP, all farms need to sample groundwater from existing wells twice during the first year. Subsequent groundwater sampling frequency is greater for farms in tier three than in tier two or one. Farms can choose to implement the groundwater sampling program individually or join a coalition that has been created specifically to perform groundwater monitoring and to support farmers with the implementation of the Agricultural Regulatory Program.

\section{Central Valley SALTS program.}

Operating at an even larger scale and affecting stakeholders beyond agriculture (e.g., wastewater treatment plants, food processing plants, urban storm water systems) is the Central Valley Salinity Alternatives for Long-Term Sustainability (CV-SALTS) program. In coordination with the RWB, it was created in 2009 by stakeholders to develop a comprehensive salt and nutrient basin plan amendment for the Central Valley that complies with the state's recycled water policy (SWRCB 2009). The development of the basin plan amendment includes a wide range of assessments by CV-SALTS: nitrate and salt source loading from agricultural, urban and industrial sources, extensive review of surface water and groundwater quality data, and development of potential management practice and infrastructure solutions.

The CV-SALTS program builds upon and is coordinated with the Central Valley Dairy Order and ILRP efforts. It focuses in particular on avoiding future salinization of the Central Valley aquifer system under SWRCB's overarching antidegradation policy. Stakeholders are organized within the Central Valley Salinity Coalition (CVSC), which is scheduled to provide its final salt and nutrient management plan (SNMP) to the RWB in 2016. As part of these efforts, a recent Strategic Salt Accumulation and Transport Study (SSALTS) compared historic water quality data to an assessment of current salt and nutrient loading in the Central Valley; it determined that approximately 1.2 million acre-feet of Central Valley groundwater needs to be desalinized annually to meet long-term irrigation and drinking water standards.

SSALTS suggests various alternatives for water treatment, including desalination and evaporation ponds. Implementation costs are estimated to be roughly $\$ 70$ billion over the next 30 years, of which $\$ 20$ billion can be raised by selling approximately 1.1 million acrefeet of ultraclean treated water annually to urban areas. These costs include some saline water being disposed of by deep injection and some being stored in salt accumulation areas on the Tulare Lake Bed (CDM Smith 2014).

\section{Challenging transitions for agriculture,} science and the regulatory community

These efforts to manage groundwater supply and groundwater quality make the agricultural community subject to an evolving set of new requirements for documentation of key farm activities, training, practice improvement, monitoring and reporting. This will be a significant and in some cases expensive shift in farming practices. It is without parallel in California's agricultural history. As was the case with the development and implementation of water quality regulatory programs in the 1970s through 1990s that targeted and significantly changed practices in industrial and urban land uses, the transition period will be challenging for this newly regulated community and likely take a generation to be fully effective.

To the degree that a more centralized, region-wide effort - rather than a farm-by-farm approach - can direct the goals of these new programs, the ILRP coalitions will have a key role in providing services to help member farmers comply, at an annual cost currently ranging from about $\$ 3$ to $\$ 7$ per acre (including regulatory fees assessed by the RWBs). Similar coordination and funding approaches may evolve within the GSAs that implement the new sustainable groundwater management legislation, with some additional funding available also through state and federal grants. But in addition to paying monitoring and compliance fees, farmers and their employees will also participate in training and continuing education, provided through the ILRP coalitions, local GSAs, UC ANR Cooperative Extension, National Resources Conservation Service, Resource Conservation Districts and others; and on many farms, significant infrastructure improvements are needed to address groundwater quality and quantity concerns, at significant cost to the farm operation (Medellin-Azuara et al. 2013).

This is not a transition period only for farmers; it is also a transition period for scientists and educators who develop and provide innovative management practices 
and training to protect groundwater quality and better understand the groundwater-agriculture interface. Agronomic and crop scientists have rarely taken into account losses of contaminants to groundwater when developing best management practices and farm recommendations.

Existing recommendations for fertilizer applications, for example, are in urgent need of revision to account for potential unwanted losses of nutrients to groundwater (Gold et al. 2013; Rosenstock et al. 2014). Another challenge for scientists is the design of groundwater monitoring networks. Existing groundwater research has developed many approaches to monitoring distinct contaminant plumes, typically a few acres in size (e.g., Einarson and Mackay 2001), but recommendations for the design of nonpoint source monitoring networks are currently lacking (Belitz et al. 2010).

Furthermore, this is a transition period for regulatory agencies, which for the first time are regulating nonpoint sources of groundwater pollution that involve large tracts of land with numerous individual landowners who are adjacent to each other and a wide range of crops, soils and management practices. For agencies, this is a situation that requires innovative strategies and a significant rethinking of existing programs that have been focused on point sources or surface water quality.

\section{Example of working with a regulation: Speed limit}

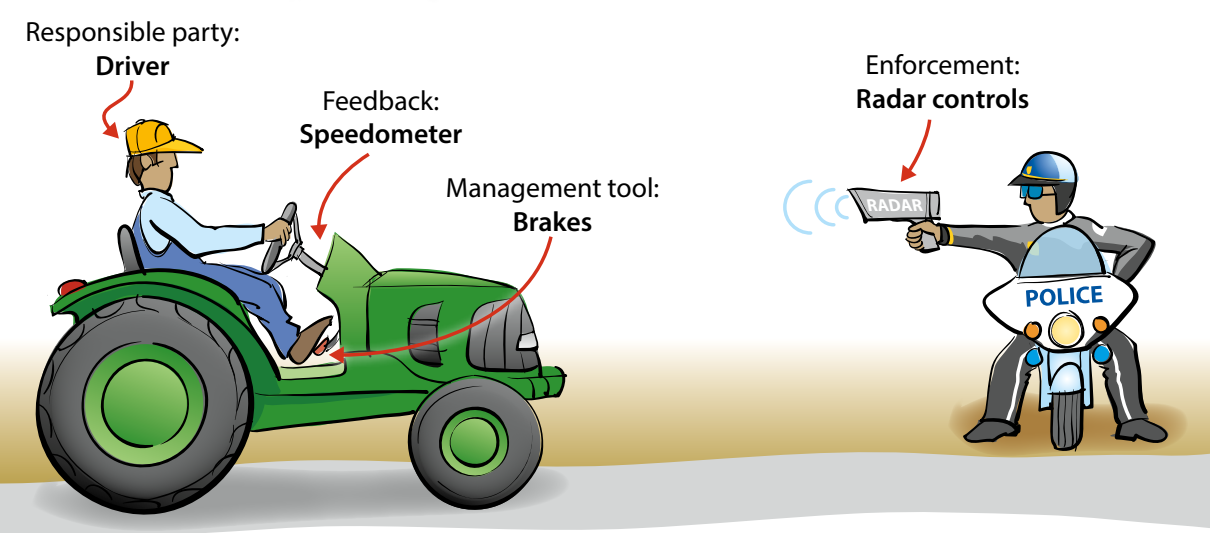

Focus: Enforcement monitoring

Alternative monitoring approach to nonpoint source:

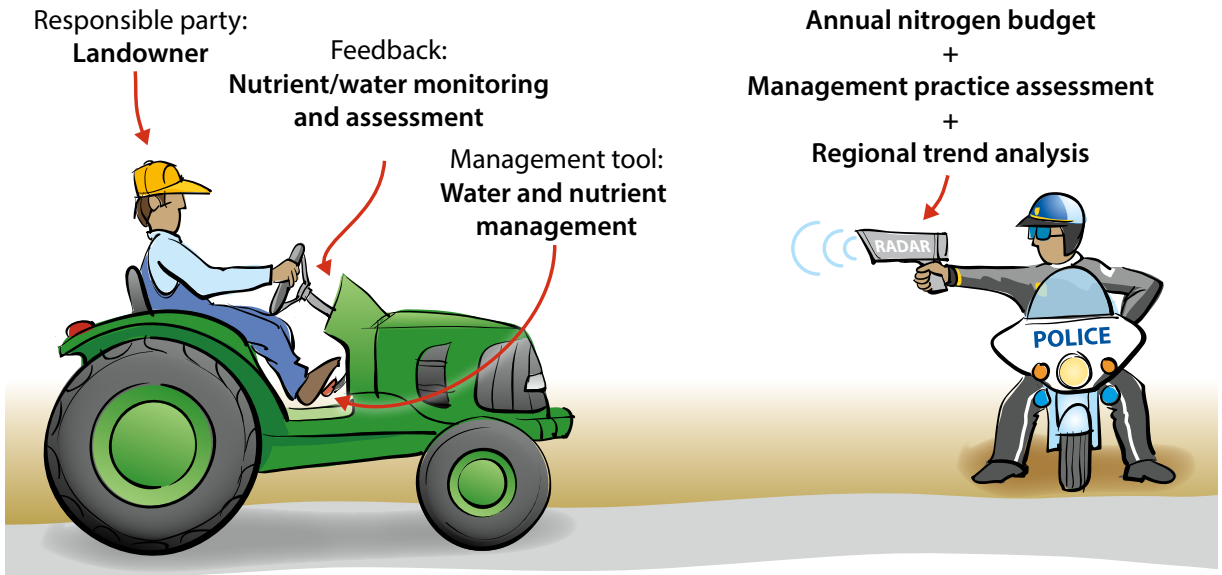

Fig. 3. Implementation of new nonpoint source monitoring programs to evaluate discharge to groundwater. A well-known enforcement program is the speed limit, which involves the driver as the responsible party, a speedometer that provides instantaneous feedback on speed, brakes and accelerator to adjust the speed, and police radar controls for enforcement. The equivalent in nonpoint source regulatory programs is the landowner as responsible party, the nutrient and water budgets as feedbacks to the landowner, nutrient and water management as the tool to adjust discharge and a three-tracked monitoring program for enforcement (see text).

For example, regulatory agencies have long focused on shallow groundwater monitoring wells as a key tool for monitoring potential waste discharges into groundwater and to detect inadvertent contaminant plumes from point sources, such as from underground gasoline storage tanks. Underground storage tanks are discrete point sources, and leaks from them can be detected by using down-gradient monitoring wells (Day et al. 2001). Agricultural irrigation, in contrast, leaks by design across broad landscapes, to flush salts from the root zone. Agricultural irrigation has therefore also been a significant source of groundwater recharge, especially irrigation from older non-efficient systems.

\section{New monitoring approaches}

Regulatory agencies have come to recognize that traditional site monitoring well networks are not the most effective tool for farm discharge monitoring. In the Central Valley Dairy Order, Central Valley ILRP and Central Coast Agricultural Order, an alternative is emerging that employs a loosely integrated three-tracked monitoring approach (fig. 3):

1. Proxy monitoring, e.g., nutrient budgets: Nitrogen budgets at the field and farm scale are used to estimate potential groundwater nitrate losses, instead of groundwater monitoring wells that would more directly observe discharge of nitrate.

2. Management practice assessments: Because discharge is not measured directly, research is needed to show the relationship between the nitrogen budget (the proxy waste discharge monitoring tool), agricultural management practices and impact to groundwater quality. In the Central Valley ILRP, this step is referred to as the management practice evaluation program.

3. Regional trend monitoring: As an insurance that the first two tracks are successful, regional long-term dynamics in groundwater quality are monitored through trend monitoring programs, implemented by farm coalitions or through a regulatory agency (e.g., California Department of Pesticide Regulation domestic well monitoring program). 
stakeholders and of their engagement in these efforts.

Sharing the costs. The new groundwater management and groundwater quality regulations and improvements involve additional costs and efforts for farmers and other local and state stakeholders and taxpayers, but they will provide long-term benefits to water users, including agriculture. Disagreements and lawsuits over how to share costs will likely continue to be part of the agricultural groundwater landscape as well.

The global long-term view. Despite the growing pains, sustainable management of groundwater supplies and protection and improvement of groundwater quality in California agricultural regions are a necessary and vital foundation for continued economic and ecosystem prosperity in these regions. If California continues to lead, nationally, this broad sustainability effort and if that leadership is demonstrable and transparent to the public, California agriculture may some day enjoy a significant economic advantage: sustainable agricultural produce is expected to be in demand among increasingly discerning consumers, including large food service providers (for instance, Menus of Change).

Finally, and most importantly, California is not alone in this challenge. Irrigated agricultural regions around the world produce $40 \%$ of global agricultural products. Many of these regions are struggling with overuse and water quality degradation of their groundwater resources, posing significant risks to global food security and political stability (Brabeck-Letmathe and Ganter 2015; University of California 2015). Meeting the sustainable groundwater challenge with forward thinking and integrated agricultural, scientific and policy programs has become a global endeavor. CA

T. Harter is UC ANR Cooperative Extension Specialist and Robert M. Hagan Endowed Chair for Water Management and Policy in the Department of Land, Air and Water Resources at UC Davis.

\section{References}

Bachand PA, Roy SB, Choperena J, Horwath WR. 2014. Implications of using on-farm flood flow capture to recharge groundwater and mitigate flood risks along the Kings River, California. Environ Sci Technol 48:13601-9.

Belitz K, Jurgens B, Landon MK, et al. 2010. Estimation of aquifer scale proportions using equal area grids: Assessment of regional scale groundwater quality. Water Resour Res 46:11. http://dx.doi.org/10.1029/2010WR009321.

Brabeck-Letmathe P, Ganter C. 2015. Water crises are a top global risk. World Economic Forum blog. January 16, 2015. https://agenda.weforum.org/2015/01/why-worldwater-crises-are-a-top-global-risk/.

Brown and Caldwell. 2015. State of the Salinas River Groundwater Basin. Salinas, CA: Monterey County Water Resources Management Agency. 240 p. www.mcwra. co.monterey.ca.us/hydrogeologic reports/documents/ State_of_the_SRGBasin_Jan16_2015.pdf.

Brush C. 2014. The California Central Valley GroundwaterSurface Water Simulation Model. California Department of Water Resources, Sacramento, CA. https://msb.water. ca.gov/documents/86728/efb1537e-653f-4cde-903869d0645ee3df

[CAWSI] California Agricultural Water Stewardship Initiative. 2015. Nutrient management webpage. Credit: Mark Lundy, UCCE. www.agwaterstewards.org/index.php/ practices/nutrient_management

California Natural Resources Agency. 2014. California Water Action Plan. http://resources.ca.gov/california_water_action_plan/.

CDM Smith. 2014. Strategic Salt Accumulation Land and Transportation Study (SSALTS) Draft Final Phase 2 Report: Development of Potential Salt Management Strategies. 189 p. www.cvsalinity.org/index.php/docs/ committee-document/technical-advisory-docs/ implementation-planning/ssalt/2857-ssalts-draft-phase2-report-development-of-potential-salt-management strategies20140902.html.

[CDWR] California Department of Water Resources. 2014a. Report to the Governor's Drought Task Force - Groundwater Basins with Potential Water Shortages and Gaps in Groundwater Monitoring, April 2014. Sacramento, CA. 51 p.

CDWR. 2014b. California Water Plan Update 2013.

Sacramento, CA. www.waterplan.water.ca.gov/docs/ cwpu2013/Final/00-CWP-Update2013_Highlights_FINAL_10-28-2014.pdf.

CDWR. 2014c. Public Update for Drought Response, November 2014. Sacramento, CA. 52 p.
Day MJ, Reinke RF, Thomson JAM. 2001. Fate and transport of fuel components blow slightly leaking underground storage tanks. Environ Forensics 2:21-8.

Dowd BM, Press D, Los Huertos M. 2008. Agricultural nonpoint source wáter pollution policy: The case of California's Central Coast. Agr Ecosyst Envion 128:151-61.

Dzurella KN, Medellin-Azuara J, Jensen VB, et al. 2012. Nitrogen source reduction to protect groundwater quality. Technical Report 3. 174 p. In: Harter T, Lund J. Addressing Nitrate in California's Drinking Water with a Focus on Tulare Lake Basin and Salinas Valley Groundwater. Report for the State Water Resources Control Board Report to the Legislature. Center for Watershed Sciences, UC Davis, CA http://groundwaternitrate.ucdavis.edu/files/139103.pdf.

Einarson MD, Mackay DM. 2001. Predicting impacts of groundwater contamination. Environ Sci Technol 35(3):67A-73A. doi:10.1021/es0122647.

Gold A, Parker D, Waskom R, et al. 2013. Advancing water resource management in agricultural, rural, and urbanizing watersheds: Enhancing university involvement. J Soil Water Conserv 68(4):337-48. doi:10.2489/jswc.68.4.337.

Harter T, Dahlke H. 2014. Out of sight, but not out of mind: California refocuses on groundwater. Calif Agr 68(3):54-5

Harter T, Lund JR, Darby J, et al. 2012. Addressing Nitrate in California's Drinking Water with a Focus on Tulare Lake Basin and Salinas Valley Groundwater. Report for the State Water Resources Control Board Report to the Legis lature. Center for Watershed Sciences, UC Davis, CA. 78 p. http://groundwaternitrate.ucdavis.edu.

Howitt RE, Kaplan J, Larson D, et al. 2009. The Economic Impacts of Central Valley Salinity. Final Report to the State Water Resources Control Board, Contract 05-417-150-0, March 20, 2009. 154 p. www.cvsalinity.org/index.php/ docs/archived-documents/1597-economicstudyucdavis032009pdf/file.html.

Howitt R, Medellin-Azuara J, Lund J, McEwan D. 2014 Preliminary 2014 Drought Economic Impact Estimates in Central Valley Agriculture. Center for Watershed Sciences, UC Davis, CA

Jurgens BC, Fram MS, Belitz K, et al. 2010. Effects of groundwater development on uranium: Central Valley, California, USA. Groundwater 48:913-28. http://ca.water. usgs.gov/pubs/2010/JurgensEtAl2010.pdf.

Lockhart KM, King AM, Harter T. 2013. Identifying sources of groundwater nitrate contamination in a large alluvial groundwater basin with highly diversified intensive agricultural production. J Contam Hydrol 151:140-54. doi:10.1016/j.jconhyd.2013.05.008.
[LWA] Larry Walker Associates, 2013. CV-SALTS Initial Conceptual Model (ICM) Technical Services - Tasks 7 and 8: Salt and Nitrate Analysis for the Central Valley Floor and a Focused Analysis of Modesto and Kings Subregions. Final Report, December 2013. 291 p. www.cvsalinity.org/index. php/docs/committee-document/technical-advisorydocs/conceptual-model-development/initial-conceptual-model-icm/2630-icm-final-report-december-2013/ file.html.

Mayzelle MM, Viers JH, Medellin-Azuara J, Harter T. 2014 Economic feasibility of irrigated agricultural land use buffers to reduce groundwater nitrate in rural drinking water sources. Water 7(1):12-37.

Medellín-Azuara J, MacEwan D, Howitt RE, et al. 2015. Hydro-economic analysis of groundwater pumping for irrigated agriculture in California's Central Valley, USA. Hydrogeol J 12:1205-16. doi:10.1007/s10040-015-1283-9

Medellín-Azuara J, Rosenstock TS, Howitt RE, et al. 2013 Agro-economic analysis of nitrate crop source reductions. J Water Res PI-ASCE 139(5):501-11. doi:10.1061/ (ASCE)WR.1943-5452.0000268.

RosenstockTS, Liptzin D, Dzurella K, et al. 2014. Agriculture's contribution to nitrate contamination of Californian groundwater (1945-2005). J Environ Qual 43(3):895-907. Rudolph DL, Devlin JF, Bekeris L. 2015. Challenges and a strategy for agricultural BMP monitoring and remediation of nitrate contamination in unconsolidated aquifers. Groundwater Monitoring Remediation 35:97-109. doi:10.1111/gwmr.12103.

[SWRCB] State Water Resources Control Board. 2009. Recycled Water Policy. Sacramento, CA. www.waterboards. ca.gov/water_issues/programs/water_recycling_policy/ docs/recycledwaterpolicy_approved.pdf.

SWRCB. 2013. Communities That Rely on a Contaminated Groundwater Source for Drinking Water. Report to the Legislature. January 2013. Sacramento, CA. 181 p.

University of California. 2015. Toward sustainable groundwater in agriculture - An international conference linking science and policy 2016. http://ag-groundwater.org/. 